\title{
Comparison of efficacy of long-acting bronchodilators in emphysema dominant and emphysema nondominant chronic obstructive pulmonary disease
}

\author{
This article was published in the following Dove Press journal: \\ International Journal of COPD \\ 3। March 201। \\ Number of times this article has been viewed
}

\author{
Keisaku Fujimoto' \\ Yoshiaki Kitaguchi ${ }^{2}$ \\ Shintaro Kanda ${ }^{2}$ \\ Kazuhisa Urushihata ${ }^{2}$ \\ Masayuki Hanaoka² \\ Keishi Kubo² \\ 'Department of Biomedical \\ Laboratory Sciences, ${ }^{2}$ First \\ Department of Internal Medicine, \\ Shinshu University School of \\ Medicine, Matsumoto, Nagano, Japan
}

Correspondence: Keisaku Fujimoto Department of Biomedical Laboratory Sciences, Shinshu University School of Health Sciences, 3-I-I Asahi, Matsumoto, Nagano, 390-862I, Japan

Tel +8I 263372393

Fax +8I 263372370

Email keisaku@shinshu-u.ac.jp

\begin{abstract}
Background: The purpose of this study was to clarify the association between morphological phenotypes according to the predominance of emphysema and efficacy of long-acting muscarinic antagonist and $\beta_{2}$ agonist bronchodilators in patients with chronic obstructive pulmonary disease (COPD).
\end{abstract}

Methods: Seventy-two patients with stable COPD treated with tiotropium $(n=41)$ or salmeterol $(n=31)$ were evaluated for pulmonary function, dynamic hyperinflation following metronome-paced incremental hyperventilation, six-minute walking distance, and St George's Respiratory Questionnaire (SGRQ) before and 2-3 months following treatment with tiotropium or salmeterol. They were then visually divided into an emphysema dominant phenotype ( $\mathrm{n}=25$ in the tiotropium-treated group and $n=22$ in the salmeterol-treated group) and an emphysema nondominant phenotype on high-resolution computed tomography, and the efficacy of the two drugs in each phenotype was retrospectively analyzed.

Results: Tiotropium significantly improved airflow limitation, oxygenation, and respiratory impedance in both the emphysema dominant and emphysema nondominant phenotypes, and improved dynamic hyperinflation, exercise capacity, and SGRQ in the emphysema dominant phenotype but not in the emphysema nondominant phenotype. Salmeterol significantly improved total score for SGRQ in the emphysema phenotype, but no significant effects on other parameters were found for either of the phenotypes.

Conclusion: These findings suggest that tiotropium is more effective than salmeterol for airflow limitation regardless of emphysema dominance, and also can improve dynamic hyperinflation in the emphysema dominant phenotype, which results in further improvement of exercise capacity and health-related quality of life.

Keywords: emphysema, dynamic hyperinflation, long-acting $\beta_{2}$ agonist, long-acting muscarinic antagonist, exercise capacity, quality of life

\section{Introduction}

Chronic obstructive pulmonary disease (COPD) is a disease state characterized by airflow limitation that is not fully reversible. ${ }^{1}$ The chronic airflow limitation is attributed to narrowing of the small airway lumen due to airway wall thickening, mucus hypersecretion, and airway collapsibility due to decreased lung elastic recoil pressure and loss of alveolar attachments. However, the relative contributions of these pathological changes toward airflow limitation vary between individuals, and the pathophysiological pathways that lead to emphysema and to small airway remodelling are independent of each other. ${ }^{2,3}$ We have already demonstrated that when patients with COPD were 
classified into phenotypes according to the presence of apparent emphysematous changes and/or the presence of airway wall thickening on chest high-resolution computed tomography (HRCT), each phenotype showed some characteristic clinical features. ${ }^{4,5}$ The emphysema nondominant phenotype, accounting for $22.7 \%$ of all the patients, showed milder disturbance of gas exchange and lung hyperinflation, and greater reversibility of airflow limitation responsive to short-acting $\beta_{2}$-agonists as compared with the emphysema dominant phenotype.

Dynamic hyperinflation is an important phenomenon causing dyspnea and restricting exercise capacity in COPD. ${ }^{6,7}$ It has been shown that improvements in dyspnea on effort following bronchodilator therapy correlate well with reductions in lung hyperinflation, as indicated by increases in inspiratory capacity. ${ }^{8}$ It was demonstrated that the rate of change in inspiratory capacity during exercise, ie, dynamic hyperinflation, correlated best with diffusion capacity, and that the subgroup with a reduced diffusion capacity (DLCO), which may be an emphysema dominant phenotype, had a significantly faster rate of dynamic hyperinflation, occurring early in exercise, than those with a preserved DLCO. ${ }^{7}$ These findings suggest that the difference in morphological features between the emphysema dominant and emphysema nondominant phenotypes may affect not only clinical features but also the therapeutic response to bronchodilators.

Of all the bronchodilators, the long-acting muscarinic antagonists are the most effective agents for COPD when used alone. It has been demonstrated that the increases in forced expiratory volume in one second $\left(\mathrm{FEV}_{1}\right)$ and forced vital capacity (FVC) following treatment with tiotropium are greater than those following treatment with salmeterol, a long-acting $\beta_{2}$-agonist. ${ }^{9,10}$ However, it has not been shown whether there are differences in efficacy between long-acting muscarinic antagonists and long-acting $\beta 2$-agonists when patients with COPD are divided into emphysema dominant and emphysema nondominant phenotypes. The purpose of the present study was to clarify the association between morphological phenotypes according to the dominancy of emphysema on chest HRCT and the efficacy of a long-acting muscarinic antagonist or a long-acting $\beta 2$-agonist in COPD patients. We retrospectively compared the therapeutic efficacy of tiotropium and salmeterol on pulmonary function, dynamic hyperinflation, exercise capacity, and health-related quality of life in the emphysema dominant and nondominant phenotypes of COPD.

\section{Materials and methods Subjects}

We recruited consecutive symptomatic patients with stable COPD, who had not yet been treated with any long-acting muscarinic antagonist or long-acting $\beta 2$-agonist, and were seen in the outpatient clinic of Shinshu University Hospital from February 2005 to July 2008. COPD was diagnosed in accordance with the GOLD (Global Initiative for Chronic Obstructive Lung Disease) guidelines. ${ }^{1}$ Exclusion criteria were any history of asthma or asthmatic symptoms, treatment with oral steroids and/or long-term oxygen therapy, and respiratory tract infection or exacerbation during the preceding three months. Seventy-two patients underwent chest HRCT and pulmonary function tests, including respiratory impedance, dynamic hyperinflation following metronomepaced incremental hyperventilation (MPIH), a six-minute walking test, and health-related quality of life evaluated by the Saint George's Respiratory Questionnaire (SGRQ) before and 2-3 months following treatment with tiotropium $18 \mu \mathrm{g}$ once daily or salmeterol $50 \mu \mathrm{g}$ twice daily, while continuing their other current therapy without any changes in dose. Of these 72 patients, 30 in the tiotropium-treated group and 27 patients in salmeterol-treated group were then enrolled in a randomized, open-label, comparative trial of the clinical efficacy of tiotropium and salmeterol in COPD, the results of which have not yet been reported. The rest of the patients were assigned to tiotropium or salmeterol purely on a clinical basis. All subjects had smoking-related COPD without $\alpha_{1}$-antitrypsin deficiency, and had a smoking history of more than 30 pack-years. In total, 41 of the 72 patients were treated with tiotropium and 31 patients were treated with salmeterol. Severity of COPD, assessed according to GOLD guidelines, was stage $1(n=3)$, stage $2(n=200)$, stage $3(n=17)$, and stage $4(n=3)$ in the tiotropium-treated group, and stage 1 $(n=4)$, stage $2(n=14)$, stage $3(n=10)$, and stage $4(n=3)$ in the salmeterol-treated group. There was no significant difference in severity of COPD between the two treatment groups. As current therapies, 16 patients were treated with inhaled corticosteroids and 20 with oral theophylline in the tiotropium-treated group, and 12 patients were treated with inhaled corticosteroids and 15 with oral theophylline in the salmeterol-treated group. Most of patients used short-acting beta-2-agonists as needed to relieve dyspnea 2-3 times per week, but did not use them on the day that the pulmonary function tests were performed. The study was approved by the institutional research ethics committee of Shinshu University School of Medicine. 


\section{Protocol}

The 41 patients treated with tiotropium and the 31 patients treated with salmeterol were divided into an emphysema dominant phenotype and emphysema nondominant phenotype according to visual findings on chest HRCT. We retrospectively compared the efficacy of tiotropium or salmeterol in each phenotype on the basis of pulmonary function tests, including respiratory impedance evaluated using an impulse oscillation system, dynamic hyperinflation following MPIH, exercise capacity evaluated by a six-minute walking test, and SGRQ. The six-minute walking test was performed according to American Thoracic Society guidelines. ${ }^{11}$ These evaluations were done between 9 am and 11 am after inhalation of tiotropium or salmeterol, and repeated 2-3 months later.

\section{Evaluation of emphysema on chest HRCT}

Evaluation for the presence of emphysema was done using a helical CT scanner (LightSpeed, General Electric, Milwaukee, WI) at full inspiration with $1-3 \mathrm{~mm}$ collimation $(120 \mathrm{kVp}$, $200 \mathrm{~mA}$, pitch 1.0). HRCT images were photographed with a window setting appropriate for the lungs (window level -700 to $-900 \mathrm{HU}$ and width $800-1000 \mathrm{HU}$ ). The presence of emphysema on HRCT was defined as well demarcated areas of decreased attenuation in comparison with a contiguous normal lung and marginated by either a very thin wall $(<1 \mathrm{~mm})$ no wall at all, and/or multiple bullae $(>1 \mathrm{~cm})$ with an upper lung field predominance. Emphysema was scored visually in bilateral upper, middle, and lower lung fields according to the method used by Goddard et al. ${ }^{12}$ The score in each field was calculated for the dimensions according to the ratio of low attenuation area as follows: score 0 , low attenuation area $<5 \%$; score $1,5 \% \leq$ low attenuation area $<25 \%$; score $2,25 \% \leq$ low attenuation area $<50 \%$; score $3,50 \% \leq$ low attenuation area $<75 \%$; score $4,75 \% \leq$ low attenuation area. The severity of emphysema was graded in accordance with the sum of scores for six dimensions as follows: grade 0 , total score $=0$; grade 1 , total score $=1-6$; grade 2 , total score $=7-12$; grade 3 , total scores $=13-18$; grade 4 , total scores $=19-24$. We defined that emphysema-dominant COPD had emphysema $\geq$ grade 2 and that emphysema nondominant COPD was emphysema grade $0-1$. Computed tomography images were analyzed independently by two pulmonologists (YK and KF) with no knowledge of the patients' clinical status.

\section{Pulmonary function tests}

Spirometry and DLCO were measured using the Chestac-8800 (Chest Co Ltd, Tokyo, Japan). Functional residual capacity was measured using a Body Box (Medgraphic, Ann Arbor, MI), after which the subject immediately inspired to total lung capacity and expired maximally to residual volume, allowing calculation of lung volume and residual volume/total lung capacity. Local Japanese reference data, ${ }^{13}$ developed by the Japanese Respiratory Society, were used to derive predicted values for $\mathrm{FEV}_{1}$ and vital capacity, and predicted values for DLCO and lung volumes (functional residual capacity, residual volume, and total lung capacity) measured by body plethysmography were determined using the formulae of Nishida et a $\mathrm{l}^{14}$ and Boren et $a l,{ }^{15}$ respectively. Respiratory impedance was measured using an impulse oscillation system (Masterscreen, Erich Jaeger, Hoechberg, Germany), as previously described. ${ }^{16,17}$ Measurements of respiratory impedance were performed during tidal breath for 30 seconds in a sitting position, supporting the subject's cheeks and mouth floor to reduce upper airway shunting. Respiratory impedance is characterized by two components, ie, respiratory resistance and reactance. Reactance undergoes a transition from negative to positive values as frequency $(f)$ increases. The resonant frequency ( $f$ res) was determined as the frequency at which reactance crossed zero and the elastic and inertial forces were equal in magnitude and opposite. Respiratory resistance and reactance at lower oscillation frequencies and respiratory resistance at higher frequencies were evaluated at oscillation frequencies of $5 \mathrm{~Hz}$ (Rrs5 and Xrs5) and $20 \mathrm{~Hz}(\operatorname{Rrs} 20)$. We also measured mean values of Rrs5 and Xrs5 separately for inspiration and expiration of tidal breath, and evaluated the difference between mean expiratory and inspiratory resistance $(\Delta R r 55)$ and reactance $(\Delta \mathrm{Xrs} 5)$. Each subject was examined at least three times and the values were averaged.

\section{Evaluation of dynamic hyperinflation following MPIH}

Dynamic hyperinflation was evaluated by MPIH, incrementally increasing the breathing rate from 20 to 30 and 40 breaths per minute according to our previous report. ${ }^{18}$ End-expiratory lung volume was measured by body plethysmography, inspiratory capacity, and vital capacity immediately after breathing at a rate of 20 breaths per minute paced by a metronome for 30 seconds. Consequently, breathing rate was increased to 30 breaths per minute and 40 breaths per minute in 30-second increments, and end-expiratory lung volume, inspiratory capacity, and vital capacity were again measured immediately after MPIH for 30 seconds at each breathing rate. Inspiratory capacity at rates of 20, 30, and 40 breaths per minute were expressed as $\mathrm{IC}_{20}, \mathrm{IC}_{30}$, and 
$\mathrm{IC}_{40}$, respectively. Dynamic hyperinflation was evaluated by the decreases in inspiratory capacity from $\mathrm{IC}_{20}$ to $\mathrm{IC}_{30}\left(\Delta \mathrm{IC}_{30}\right.$; $\left.\mathrm{IC}_{30}-\mathrm{IC}_{20}\right)$ and from $\mathrm{IC}_{20}$ to $\mathrm{IC}_{40}\left(\Delta \mathrm{IC}_{40} ; \mathrm{IC}_{40}-\mathrm{IC}_{20}\right)$.

\section{Data analysis}

The values shown in the text, figures, and tables represent the mean \pm standard error of the mean. Comparison of variables at baseline and at the end of the study period was performed using paired $t$-tests. Simple correlations between variables were examined by calculating Pearson's product correlation coefficient. Variables were compared using the KruskalWallis test, followed by multiple comparisons among groups in combination with phenotypes using the nonparametric Scheffe method. All statistical analyses were performed using Windows-compatible software (Stat Flex version 5.0; Artech, Osaka, Japan). A value of $P<0.05$ was considered significant for the results of all statistical analyses.

\section{Results}

\section{Characteristics of emphysema phenotypes before treatment with tiotropium or salmeterol}

Twenty-five of 41 patients treated with tiotropium and 22 of 31 patients treated with salmeterol were classified as having emphysema dominant COPD (the emphysema phenotype). The remaining patients, ie, 16 of 41 tiotropium-treated patients and nine of 31 salmeterol-treated patients, were classified as having emphysema nondominant COPD (the nonemphysema phenotype).

In both tiotropium-treated and salmeterol-treated patients, body mass index, $\mathrm{FEV}_{1}, \mathrm{FEV}_{1} / \mathrm{FVC}$, and DLCO were significantly lower for the emphysema phenotype than for the nonemphysema phenotype (Table 1). The mean values of inspiratory capacity and arterial oxygen tension $\left(\mathrm{PaO}_{2}\right)$ were lower and residual volume/total lung capacity was higher in emphysema phenotype. There were significant differences in inspiratory capacity for the tiotropium-treated group and in $\mathrm{PaO}_{2}$ for the salmeterol-treated group. There were no significant differences in low attenuation area scores between the tiotropium-treated and salmeterol-treated groups for either phenotype.

\section{Pulmonary function tests}

$\mathrm{FEV}_{1}$ and $\mathrm{PaO}_{2}$ were significantly increased, Rrs5 was significantly decreased, and Xrs5 significantly less negative following treatment with tiotropium for both phenotypes (Table 2). The increase in $\mathrm{PaO}_{2}$ was significantly greater for the nonemphysema phenotype. Furthermore, Rrs5, Rrs20, and fres were decreased in the emphysema phenotype, and within-breath changes in Xrs5 were reduced significantly for the nonemphysema phenotype. There were no significant differences in improvement of these pulmonary function parameters, except for $\mathrm{PaO}_{2}$, between the phenotypes. There were no significant changes following treatment with

Table I Characteristics of patients with chronic obstructive pulmonary disease in the tiotropium-treated and salmeterol-treated groups

\begin{tabular}{|c|c|c|c|c|}
\hline & \multicolumn{2}{|c|}{ Tiotropium-treated group } & \multicolumn{2}{|c|}{ Salmeterol-treated group } \\
\hline & Emphysema & Nonemphysema & Emphysema & Nonemphysema \\
\hline Number & 25 & 16 & 22 & 9 \\
\hline Age, years & $75.3 \pm 1.3$ & $71.4 \pm 1.8$ & $72.6 \pm 1.3$ & $69.8 \pm 2.5$ \\
\hline Gender, M/F & $22 / 3$ & $14 / 2$ & $22 / 0$ & $8 / 1$ \\
\hline $\mathrm{BMI}, \mathrm{kg} / \mathrm{m}^{2}$ & $19.9 \pm 0.5^{t t}$ & $23.4 \pm 0.7$ & $20.8 \pm 0.5^{\dagger \dagger}$ & $24.8 \pm 0.8$ \\
\hline VC, \% pred & $89.0 \pm 3.8$ & $99.7 \pm 4.3$ & $96.3 \pm 4.3$ & $102.8 \pm 6.5$ \\
\hline IC, L & $1.73 \pm 0.10^{+.8}$ & $2.25 \pm 0.18$ & $2.10 \pm 0.11$ & $2.4 I \pm 0.26$ \\
\hline $\mathrm{FEV}_{1}$, \% pred & $48.3 \pm 3.3^{t+}$ & $65.1 \pm 3.3$ & $50.7 \pm 4.0^{\dagger}$ & $72.4 \pm 7.5$ \\
\hline $\mathrm{FEV}_{1} / \mathrm{FVC}, \%$ & $45.1 \pm 1.7^{t+}$ & $57.4 \pm 2.2$ & $45.4 \pm 2.2^{\dagger \dagger}$ & $59.3 \pm 3.8$ \\
\hline FRC, $\%$ of pred & $120.9 \pm 6.8$ & $120.9 \pm 8.9$ & $126.1 \pm 7.2$ & $125.5 \pm 15.9$ \\
\hline $\mathrm{RV}, \%$ of pred & $191.3 \pm 13.8$ & $165.0 \pm 13.0$ & $210.9 \pm 14.9$ & $179.7 \pm 21.6$ \\
\hline TLC, \% pred & $119.5 \pm 4.3$ & $117.7 \pm 5.7$ & $126.9 \pm 5.2$ & $118.1 \pm 7.5$ \\
\hline RV/TLC, \% & $54.3 \pm 1.9$ & $46.6 \pm 2.5$ & $52.2 \pm 2.1$ & $45.9 \pm 3.1$ \\
\hline DLCO, \% pre. & $49.0 \pm 3.7^{t t}$ & $66.2 \pm 3.6$ & $54.5 \pm 4.1^{\dagger}$ & $75.0 \pm 6.2$ \\
\hline $\mathrm{PaO}_{2}$, Torr & $65.1 \pm 1.7$ & $70.0 \pm 1.6$ & $66.4 \pm 1.6^{\dagger}$ & $73.7 \pm 2.1$ \\
\hline $\mathrm{PaCO}_{2}$, Torr & $39.6 \pm 1.0$ & $39.3 \pm 1.6$ & $40.0 \pm 0.8$ & $39.6 \pm 1.4$ \\
\hline LAA score & $18.5 \pm 1.2^{t \dagger}$ & $2.2 \pm 0.5$ & $18.6 \pm 1.0^{t \dagger}$ & $0.8 \pm 0.7$ \\
\hline
\end{tabular}

Notes: ${ }^{\dagger} P<0.05 ;{ }^{\dagger t P}<0.0$ I versus nonemphysema phenotype; $\$ P<0.05$ versus salmeterol-treated group. Values are mean \pm standard error of the mean. Abbreviations: BMI, body mass index; IC, inspiratory capacity; LAA, low attenuation area; RV, residual volume; TLC, total lung capacity; DLCO, carbon monoxide diffusion test; $\mathrm{PaCO}_{2}$, arterial carbon dioxide tension; $\mathrm{PaO}_{2}$, arterial oxygen tension; $\mathrm{FEV}$, forced expiratory volume in I second; FVC, forced vital capacity; pred, predicted. 
Table 2 Effects of tiotropium or salmeterol on pulmonary function tests in emphysema and non-emphysema chronic obstructive pulmonary disease phenotypes

\begin{tabular}{|c|c|c|c|c|c|c|}
\hline & \multicolumn{3}{|c|}{ Emphysema phenotype } & \multicolumn{3}{|c|}{ Nonemphysema phenotype } \\
\hline & Pre & Post & $\Delta$ Pre-post & Pre & Post & $\Delta$ Pre-post \\
\hline \multicolumn{7}{|c|}{ Tiotropium-treated group } \\
\hline $\mathrm{FEV}_{1}, \mathrm{~L}$ & $1.17 \pm 0.09^{\dagger+}$ & $1.25 \pm 0.10 *, \dagger \dagger$ & $0.08 \pm 0.03$ & $1.71 \pm 0.14$ & $1.84 \pm 0.16 *$ & $0.13 \pm 0.05$ \\
\hline FRC & $4.31 \pm 0.22$ & $4.27 \pm 0.20$ & $-0.05 \pm 0.14$ & $3.86 \pm 0.26$ & $3.71 \pm 0.24$ & $-0.15 \pm 0.13$ \\
\hline RV & $3.16 \pm 0.22$ & $3.12 \pm 0.21$ & $-0.04 \pm 0.16$ & $2.82 \pm 0.24$ & $2.59 \pm 0.19$ & $-0.23 \pm 0.18$ \\
\hline RV/TLC, \% & $53.2 \pm 2.1$ & $52.3 \pm 2.3^{\dagger}$ & $-0.85 \pm 1.49$ & $46.6 \pm 2.5$ & $44.4 \pm 2.0$ & $-2.15 \pm 2.24$ \\
\hline $\mathrm{PaO}_{2}$ & $64.9 \pm 1.7$ & $67.3 \pm 1.9^{*, t \dagger}$ & $2.3 \pm 1.1^{t+}$ & $69.1 \pm 1.8$ & $77.7 \pm 2.8 * *$ & $8.6 \pm 2.0^{\S}$ \\
\hline $\operatorname{Rrs} 5, \mathrm{kPa} \cdot \mathrm{s} / \mathrm{L}$ & $0.44 \pm 0.03$ & $0.35 \pm 0.02 * *$ & $-0.08 \pm 0.03^{\S \S}$ & $0.39 \pm 0.04$ & $0.32 \pm 0.04 *$ & $-0.07 \pm 0.02$ \\
\hline $\operatorname{Rrs5}-\operatorname{Rrs} 20, \mathrm{kPa} \cdot \mathrm{s} / \mathrm{L}$ & $0.16 \pm 0.03$ & $0.10 \pm 0.02 * *$ & $-0.06 \pm 0.02$ & $0.12 \pm 0.03$ & $0.06 \pm 0.04$ & $-0.07 \pm 0.04$ \\
\hline $\mathrm{Xrs} 5, \mathrm{kPa} \cdot \mathrm{s} / \mathrm{L}$ & $-0.28 \pm 0.04$ & $-0.20 \pm 0.02 *$ & $0.08 \pm 0.04^{\S}$ & $-0.21 \pm 0.04$ & $-0.16 \pm 0.03 *$ & $0.05 \pm 0.02$ \\
\hline$\Delta \mathrm{Xrs} 5, \mathrm{kPa} \cdot \mathrm{s} / \mathrm{L}$ & $-0.12 \pm 0.04$ & $-0.06 \pm 0.03$ & $0.07 \pm 0.04^{\S}$ & $-0.07 \pm 0.05$ & $-0.02 \pm 0.03 *$ & $0.06 \pm 0.03$ \\
\hline fres, $\mathrm{Hz}$ & $30.9 \pm 1.9^{t \dagger}$ & $25.9 \pm 1.6^{* *, \dagger}$ & $-5.0 \pm 1.3$ & $22.6 \pm 2.0$ & $19.2 \pm 2.1$ & $-3.5 \pm 2.0$ \\
\hline \multicolumn{7}{|c|}{ Salmeterol-treated group } \\
\hline $\mathrm{FEV}_{1}, \mathrm{~L}$ & $1.31 \pm 0.10^{\dagger}$ & $1.34 \pm 0.10^{\dagger}$ & $0.02 \pm 0.03$ & $1.89 \pm 0.26$ & $1.89 \pm 0.26$ & $0.00 \pm 0.04$ \\
\hline FRC & $4.63 \pm 0.31$ & $4.58 \pm 0.27$ & $-0.05 \pm 0.16$ & $3.72 \pm 0.4 \mathrm{I}$ & $3.66 \pm 0.28$ & $-0.06 \pm 0.33$ \\
\hline RV & $3.43 \pm 0.29$ & $3.27 \pm 0.28$ & $-0.17 \pm 0.23$ & $2.80 \pm 0.39$ & $2.50 \pm 0.20$ & $-0.30 \pm 0.38$ \\
\hline RV/TLC,\% & $51.8 \pm 2.1$ & $49.8 \pm 2.6$ & $-2.1 \pm 1.8$ & $45.9 \pm 3.1$ & $43.3 \pm 3.0$ & $-2.7 \pm 3.2$ \\
\hline $\mathrm{PaO}_{2}$, Torr & $66.4 \pm 1.6^{\dagger}$ & $66.9 \pm 1.6^{t \dagger}$ & $0.5 \pm 1.2$ & $73.7 \pm 2.1$ & $76.0 \pm 2.4$ & $2.3 \pm 1.6$ \\
\hline $\mathrm{Rrs} 5, \mathrm{kPa} \cdot \mathrm{s} / \mathrm{L}$ & $0.37 \pm 0.04$ & $0.40 \pm 0.04$ & $0.02 \pm 0.02^{\dagger}$ & $0.41 \pm 0.04$ & $0.34 \pm 0.03$ & $-0.07 \pm 0.03$ \\
\hline $\operatorname{Rrs} 5-\operatorname{Rrs} 20, \mathrm{kPa} \cdot \mathrm{s} / \mathrm{L}$ & $0.13 \pm 0.03$ & $0.13 \pm 0.04$ & $-0.00 \pm 0.03$ & $0.12 \pm 0.02$ & $0.07 \pm 0.02$ & $-0.05 \pm 0.02$ \\
\hline $\mathrm{Xrs} 5, \mathrm{kPa} \cdot \mathrm{s} / \mathrm{L}$ & $-0.19 \pm 0.03$ & $-0.23 \pm 0.03$ & $-0.04 \pm 0.02$ & $-0.19 \pm 0.04$ & $-0.14 \pm 0.03$ & $0.04 \pm 0.04$ \\
\hline$\Delta \mathrm{Xrs} 5, \mathrm{kPa} \cdot \mathrm{s} / \mathrm{L}$ & $-0.08 \pm 0.03$ & $-0.13 \pm 0.05$ & $-0.05 \pm 0.04$ & $-0.02 \pm 0.03$ & $0.02 \pm 0.01$ & $0.04 \pm 0.03$ \\
\hline fres, $\mathrm{Hz}$ & $27.4 \pm 1.7$ & $25.4 \pm 1.8^{\dagger \dagger}$ & $-2.0 \pm \mathrm{I} . \mathrm{I}^{\dagger}$ & $24.1 \pm 3.3$ & $16.7 \pm 2.0^{*}$ & $7.4 \pm 2.4$ \\
\hline
\end{tabular}

Notes: Values are mean \pm standard error of the mean. $* P<0.05$ and $* * P<0.01$ versus pretreatment; ${ }^{\dagger} P<0.05$ and $t+P<0.01$ versus nonemphysema phenotype, $\$ p<0.05$ and ${ }^{\$} P<0.01$ versus salmeterol-treated group.

Abbreviations: Rrs 5 and Rrs20, respiratory resistances at $5 \mathrm{~Hz}$ and $20 \mathrm{~Hz}$ frequencies; Xrs5, respiratory reactance at $5 \mathrm{~Hz}$ frequencies; $\Delta$ Xrs 5 , within-breath changes in

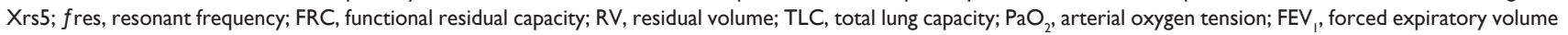
in I second; FVC, forced vital capacity.

salmeterol in any of the pulmonary function tests, except for fres in both phenotypes. On the whole, the efficacy of tiotropium for pulmonary function was superior to that of salmeterol for both phenotypes. Significant greater improvements in Rrs5, Xrs5, and $\Delta$ Xrs5 for the emphysema phenotype and in $\mathrm{PaO}_{2}$ for the nonemphysema phenotype were found after tiotropium than after salmeterol.

\section{Dynamic hyperinflation following MPIH}

Inspiratory capacity was incrementally decreased as breathing rate was increased from 20 to 40 breaths per minute in all patients before treatment with tiotropium or salmeterol, regardless of phenotype (Table 3 ). In the tiotropiumtreated group, the inspiratory capacity at each breathing rate was significantly lower and dynamic hyperinflation, expressed as the decrease in inspiratory capacity following $\mathrm{MPIH}\left(\Delta \mathrm{IC}_{30}\right.$ and $\left.\Delta \mathrm{IC}_{40}\right)$, was significantly greater for the emphysema phenotype than for the nonemphysema phenotype. $\mathrm{IC}_{30}$ and $\mathrm{IC}_{40}$ were significantly increased and $\Delta \mathrm{IC}_{40}$ was significantly decreased following treatment with tiotropium for the emphysema phenotype, but not for the nonemphysema phenotype. It has been demonstrated that the extent of dynamic hyperinflation following exercise is affected by inspiratory capacity at baseline. ${ }^{7}$ Therefore, we corrected $\Delta \mathrm{IC}_{30}$ and $\Delta \mathrm{IC}_{40}$ by $\mathrm{IC}_{20}$, and expressed these as percentage decreases in inspiratory capacity, ie, as $\Delta \mathrm{IC}_{30} / \mathrm{IC}_{20}$ and $\Delta \mathrm{IC}_{40} / \mathrm{IC}_{20}$. Both $\Delta \mathrm{IC}_{30} / \mathrm{IC}_{20}$ and $\Delta \mathrm{IC}_{40} /$ $\mathrm{IC}_{20}$ were also significantly reduced following treatment with tiotropium only for the emphysema phenotype. There was a significant correlation between low attenuation area score and $\Delta \mathrm{IC}_{40}(\mathrm{r}=0.40, P<0.05)$ and $\Delta \mathrm{IC}_{40} / \mathrm{IC}_{20}$ ( $\mathrm{r}=0.39, P<0.05)$ in the tiotropium-treated group. In the salmeterol-treated group, significant improvements in lung hyperinflation at each respiratory rate and dynamic hyperinflation following treatment could not be obtained for either phenotype.

\section{Six-minute walking test and SGRQ}

Patients with the emphysema phenotype showed severe desaturation during the walking test when compared with those having the nonemphysema phenotype (Table 4). Six-minute walking distance was significantly increased 
Table 3 Effects of tiotropium or salmeterol on dynamic hyperinflation following metronome-paced incremental hyperventilation in emphysema and nonemphysema chronic obstructive pulmonary disease phenotypes

\begin{tabular}{|c|c|c|c|c|c|c|}
\hline & \multicolumn{3}{|c|}{ Emphysema phenotype } & \multicolumn{3}{|c|}{ Nonemphysema phenotype } \\
\hline & Pre & Post & $\Delta$ Pre-Post & Pre & Post & $\Delta$ Pre-post \\
\hline \multicolumn{7}{|c|}{ Tiotropium-treated group } \\
\hline $\mathrm{IC}_{20}, \mathrm{~L}$ & $1.5 \mathrm{I} \pm 0.09^{\dagger}$ & $1.53 \pm 0.10^{\dagger}$ & $0.03 \pm 0.06$ & $1.90 \pm 0.18$ & $1.98 \pm 0.16$ & $0.08 \pm 0.07$ \\
\hline $\mathrm{IC}_{30}, \mathrm{~L}$ & $1.23 \pm 0.09+1, .8$ & $1.37 \pm 0.09 *,+t$ & $0.14 \pm 0.06^{\S}$ & $1.80 \pm 0.15$ & $1.97 \pm 0.17$ & $0.17 \pm 0.10$ \\
\hline $\mathrm{IC}_{40}, \mathrm{~L}$ & $1.09 \pm 0.08^{+t, \S}$ & $1.26 \pm 0.09 * *, \dagger$ & $0.17 \pm 0.05^{\S}$ & $1.72 \pm 0.17$ & $1.74 \pm 0.18$ & $0.02 \pm 0.11$ \\
\hline$\Delta \mathrm{I} \mathrm{C}_{30}, \mathrm{~L}$ & $-0.28 \pm 0.05^{\dagger, \delta}$ & $-0.16 \pm 0.04^{\dagger}$ & $0.11 \pm 0.06^{\S 5}$ & $-0.10 \pm 0.06$ & $-0.00 \pm 0.05$ & $0.09 \pm 0.07$ \\
\hline$\Delta \mathrm{IC}_{40}, \mathrm{~L}$ & $-0.42 \pm 0.06^{t+. \S}$ & $-0.28 \pm 0.05^{*}$ & $0.14 \pm 0.06^{+.89}$ & $-0.14 \pm 0.05$ & $-0.21 \pm 0.05$ & $-0.07 \pm 0.08$ \\
\hline$\Delta \mathrm{IC} \mathrm{C}_{30} / \mathrm{IC} \mathrm{C}_{20}, \%$ & $-18.1 \pm 2.7$ & $-10.1 \pm 2.2^{*}$ & $7.9 \pm 3.6^{\S}$ & $-2.4 \pm 3.2$ & $-0.6 \pm 2.9$ & $1.9 \pm 4.5$ \\
\hline$\Delta \mathrm{IC} \mathrm{C}_{40} / \mathrm{IC} \mathrm{C}_{20} \%$ & $-27.3 \pm 3.3$ & $-18.0 \pm 2.4^{*}$ & $9.3 \pm 3.7^{+.8}$ & $-5.9 \pm 3.1$ & $-12.6 \pm 3.8$ & $-6.6 \pm 5.9$ \\
\hline \multicolumn{7}{|c|}{ Salmeterol-treated group } \\
\hline $\mathrm{IC}_{20}, \mathrm{~L}$ & $1.65 \pm 0.12$ & $1.75 \pm 0.11$ & $0.10 \pm 0.08$ & $2.02 \pm 0.23$ & $1.98 \pm 0.24$ & $-0.04 \pm 0.08$ \\
\hline $\mathrm{IC}_{30}, \mathrm{~L}$ & $1.57 \pm 0.12$ & $1.51 \pm 0.10$ & $-0.06 \pm 0.05$ & $1.87 \pm 0.25$ & $1.86 \pm 0.21$ & $-0.01 \pm 0.08$ \\
\hline$I_{40}, \mathrm{~L}$ & $1.44 \pm 0.11$ & $1.40 \pm 0.09$ & $-0.04 \pm 0.07$ & $1.68 \pm 0.26$ & $1.69 \pm 0.20$ & $0.01 \pm 0.13$ \\
\hline$\Delta \mathrm{I} \mathrm{C}_{30}, \mathrm{~L}$ & $-0.08 \pm 0.06$ & $-0.24 \pm 0.05$ & $-0.16 \pm 0.08^{\dagger}$ & $-0.15 \pm 0.05$ & $-0.12 \pm 0.06$ & $0.03 \pm 0.06$ \\
\hline$\Delta \mathrm{IC}_{40}, \mathrm{~L}$ & $-0.21 \pm 0.07$ & $-0.35 \pm 0.06$ & $-0.14 \pm 0.09$ & $-0.35 \pm 0.12$ & $-0.29 \pm 0.11$ & $0.05 \pm 0.14$ \\
\hline$\Delta \mathrm{IC} \mathrm{C}_{30} / \mathrm{IC} \mathrm{C}_{20}, \%$ & $-3.6 \pm 4.8$ & $-12.9 \pm 2.8$ & $-9.2 \pm 5.6$ & $-8.6 \pm 2.5$ & $-5.0 \pm 3.1$ & $3.6 \pm 3.8$ \\
\hline$\Delta \mathrm{IC} \mathrm{C}_{40} / \mathrm{IC} \mathrm{C}_{20}, \%$ & $-11.7 \pm 5.5$ & $-19.2 \pm 2.6$ & $-7.5 \pm 6.0$ & $-17.9 \pm 4.8$ & $-13.5 \pm 5.2$ & $4.4 \pm 6.0$ \\
\hline
\end{tabular}

Notes: Values are mean \pm standard error of the mean. ${ }^{*} P<0.05$ and $* * P<0.01$ versus pretreatment; ${ }^{t} P<0.05$ and ${ }^{t+P}<0.01$ versus nonemphysema phenotype; $\$ P<0.05$ and $\$ \$ P<0.01$ versus salmeterol-treated group.

Abbreviations: $\mathrm{IC}_{20}, \mathrm{IC}_{30}$, and $\mathrm{IC}_{40}$, inspiratory capacity at the each rate of 20, 30, and 40 breaths per minute; $\Delta \mathrm{IC} \mathrm{C}_{30}$ and $\Delta \mathrm{IC} \mathrm{C}_{40}$, decreases in $\mathrm{IC}$ from IC $\mathrm{C}_{20}$ to $\mathrm{IC} \mathrm{C}_{30}\left(\mathrm{IC} \mathrm{C}_{30}-\mathrm{IC}_{20}\right)$ and from $I C_{20}$ to $I C_{40}\left(I_{40}^{30^{\circ}}-I C_{20}\right)$.

following treatment with tiotropium for the emphysema phenotype. However, significant increases in six-minute walking distance were not observed for the nonemphysema phenotype in the tiotropium-treated group or for either phenotype in the salmeterol-treated group.

Following treatment with tiotropium, the SGRQ score and the scores for the impact and symptom domains were significantly decreased by more than four points, representing the minimal clinically important difference, for the emphysema phenotype. In contrast, a significant decrease was observed only in the symptom domain score for the nonemphysema phenotype in the tiotropium-treated group. In the salmeterol-treated group, the total score was significantly decreased for the emphysema phenotype. However, in the nonemphysema phenotype, only the scores for activity and symptom domains were significantly decreased. There were no significant differences in improvement of health-related quality of life according to phenotype or treatment group.

\section{Discussion}

Treatment with tiotropium for 2-3 months resulted in significant improvements in airflow limitation, oxygenation, and respiratory impedance for both the emphysema dominant and nondominant phenotypes of COPD. Furthermore, tiotropium significantly improved dynamic hyperinflation, exercise capacity, and health-related quality of life for the emphysema phenotype, but not for the emphysema nondominant phenotype. On the other hand, in the salmeterol-treated group, significant improvements in pulmonary function, dynamic hyperinflation, and exercise capacity could not be obtained for either phenotype. Only the total score on the SGRQ for the emphysema phenotype decreased significantly following treatment with salmeterol. These findings suggest that tiotropium is more effective than salmeterol for airflow limitation, regardless of predominance of emphysema, and also can improve dynamic hyperinflation in the emphysema dominant phenotype, which may contribute to further improvement in exercise capacity and health-related quality of life.

A limitation of this retrospective study is lack of statistical power because the sample size was small for the nonemphysema phenotype ( $\mathrm{n}=9$ in the salmeterol-treated group and $n=16$ in the tiotropium-treated group) which is generally lower, accounting for only about $22 \%$ of COPD. The other main limitation was that the assessment of emphysema was done by a visual scoring method, rather than using software-based quantification of emphysema. However, the reproducibility of visual scoring had been demonstrated in our previous report. ${ }^{5}$ 
Table 4 Effects of tiotropium or salmeterol on exercise capacity and St Georges' Respiratory Questionnaire scores in emphysema and nonemphysema chronic obstructive pulmonary disease phenotypes

\begin{tabular}{|c|c|c|c|c|c|c|}
\hline & \multicolumn{3}{|c|}{ Emphysema phenotype } & \multicolumn{3}{|c|}{ Nonemphysema phenotype } \\
\hline & Pre & Post & $\Delta$ Pre-post & Pre & Post & $\Delta$ Pre-post \\
\hline \multicolumn{7}{|c|}{ Tiotropium-treated group } \\
\hline 6MWD, m & $402.6 \pm 19.8$ & $428.9 \pm 16.9 * *$ & $26.3 \pm 8.7$ & $426.8 \pm 23.6$ & $451.4 \pm 28.3$ & $24.6 \pm 14.2$ \\
\hline Lowest $\mathrm{SpO}_{2}, \%$ & $88.6 \pm 1.6^{\dagger}$ & $87.9 \pm 1.2^{\dagger}$ & $-0.7 \pm 0.7$ & $92.8 \pm 0.7$ & $92.0 \pm 0.7$ & $-0.8 \pm 0.4$ \\
\hline PRmax, beats/minute & $113.6 \pm 3.6$ & $115.2 \pm 3.2$ & $1.5 \pm 3.4$ & $120.7 \pm 4.6$ & $125.3 \pm 6.0$ & $4.6 \pm 3.8$ \\
\hline BSmax & $5.2 \pm 0.6$ & $5.8 \pm 0.5^{+1 \$ \S}$ & $0.5 \pm 0.5^{\S}$ & $3.4 \pm 0.7$ & $3.2 \pm 0.6$ & $-0.2 \pm 0.6$ \\
\hline Symptom & $55.3 \pm 3.6$ & $46.6 \pm 3.5^{*}$ & $-8.7 \pm 3.7$ & $46.0 \pm 5.3$ & $35.3 \pm 4.2^{*}$ & $-10.7 \pm 4.1$ \\
\hline Active & $64.5 \pm 4.0^{\S}$ & $56.3 \pm 4.3^{\dagger}$ & $-8.2 \pm 4.5$ & $7.9 \pm 11.0$ & $36.3 \pm 8.2$ & $-11.6 \pm 6.6$ \\
\hline Impact & $29.9 \pm 3.2$ & $24.2 \pm 2.9^{*}$ & $-5.6 \pm 2.5$ & $19.5 \pm 5.4$ & $15.2 \pm 3.9$ & $-4.3 \pm 4.1$ \\
\hline Total & $46.7 \pm 3.0$ & $39.4 \pm 2.7^{* *, \dagger}$ & $-7.2 \pm 2.3$ & $35.1 \pm 6.4$ & $26.9 \pm 4.6$ & $-8.2 \pm 4.2$ \\
\hline \multicolumn{7}{|c|}{ Salmeterol-treated group } \\
\hline 6MWD, m & $414 \pm 24$ & $438 \pm 20$ & $23 \pm 16$ & $484 \pm 31$ & $487 \pm 24$ & $3.0 \pm 19.0$ \\
\hline Lowest $\mathrm{SpO}_{2}, \%$ & $87.5 \pm 1.4^{\dagger}$ & $85.3 \pm 1.5^{*,+t}$ & $-2.2 \pm 1.0$ & $92.3 \pm 0.5$ & $92.5 \pm 0.7$ & $0.3 \pm 0.6$ \\
\hline PRmax, beats/minute & $115.7 \pm 3.8$ & $117.4 \pm 3.3$ & $1.7 \pm 2.4$ & $114.4 \pm 8.2$ & $112.6 \pm 4.3$ & $-1.8 \pm 8.6$ \\
\hline BSmax & $3.9 \pm 0.6$ & $3.5 \pm 0.5$ & $-0.4 \pm 0.4$ & $3.4 \pm 1.0$ & $3.2 \pm 1.0$ & $-0.2 \pm 0.3$ \\
\hline Symptom & $49.1 \pm 3.7$ & $41.9 \pm 3.5$ & $-7.2 \pm 4.1$ & $46.1 \pm 9.2$ & $36.0 \pm 7.5^{*}$ & $-10.1 \pm 3.9$ \\
\hline Active & $51.5 \pm 5.1$ & $45.9 \pm 5.1$ & $-5.6 \pm 3.2$ & $46.0 \pm 11.6$ & $31.9 \pm 10.7^{*}$ & $-14.1 \pm 5.7$ \\
\hline Impact & $23.2 \pm 3.3$ & $18.9 \pm 3.3$ & $-4.3 \pm 2.4$ & $26.1 \pm 7.6$ & $19.1 \pm 6.1$ & $-7.0 \pm 3.6$ \\
\hline Total & $38.6 \pm 3.5$ & $33.0 \pm 3.2^{*}$ & $-5.5 \pm 2.4$ & $37.5 \pm 8.5$ & $29.3 \pm 7.4$ & $-8.1 \pm 4.0$ \\
\hline
\end{tabular}

Notes: Values are mean \pm standard error of the mean. $* P<0.05$ and $* * P<0.01$ versus pretreatment; ${ }^{\dagger} P<0.05$ versus nonemphysema phenotype; $\$ p<0.05$ and ${ }^{\$ \S} P<0.01$ versus salmeterol-treated group.

Abbreviations: 6MWD, six-minute walking distance; PRmax, maximum pulse rate; BSmax, maximum Borg scale.

The efficacy of long-acting muscarinic antagonists for improving pulmonary function has been reported to be superior to that of long-acting $\beta 2$-agonists, ${ }^{10,19}$ and greater improvements in pulmonary function following treatment with tiotropium were found when compared with use of salmeterol in our study. When the patients were divided according to emphysema dominant and nondominant phenotypes, improvement in airflow limitation was found regardless of the predominance of emphysema.

Dynamic hyperinflation is usually evaluated by the decrease in inspiratory capacity during exercise. Gelb et $\mathrm{al}^{20}$ have demonstrated the utility of the metronomepaced hyperventilation (MPH) technique for evaluation of dynamic hyperinflation, which is dependent on increasing breathing frequency. We have also demonstrated a stepwise decrease in inspiratory capacity consistent with increased end-expiratory lung volume following the incremental increase of breathing frequency from 20 to 40 breaths per minute in COPD, but not in never-smokers without COPD, and the dynamic hyperinflation following MPIH was reduced by the inhalation of a short-acting $\beta 2$-agonist. ${ }^{18}$ In this study, tiotropium significantly reduced dynamic hyperinflation in the emphysema phenotype but not in the nonemphysema phenotype. It has been demonstrated that the total extent of changes in inspiratory capacity during exercise is determined primarily by resting volume constraints, ie, inspiratory capacity at rest. However, the rate of change in inspiratory capacity during exercise correlated best with diffusion capacity, and the subgroup with greater lung hyperinflation and greater reduction in DLCO had a significantly faster rate of dynamic hyperinflation, occurring early in exercise, than the subgroup with preserved DLCO. ${ }^{7}$ In this study, tiotropium-treated patients with the emphysema phenotype having lower inspiratory capacity and DLCO showed greater dynamic hyperinflation compared with patients with the nonemphysema phenotype. Decreased lung elastic recoil and loss of alveolar attachments due to alveolar destruction contribute importantly to airway collapsibility and closure during expiration, which may easily lead to dynamic hyperinflation.

O'Donnell et $\mathrm{al}^{21}$ demonstrated that treatment with tiotropium for six weeks resulted in sustained reduction of end-expiratory lung volume at rest and during exercise, and significantly improved both exertional dyspnea and exercise capacity in 96 patients with moderate-to-severe COPD. Gelb et al ${ }^{20}$ evaluated dynamic hyperinflation by the decrease in inspiratory capacity following MPH at twice the resting respiratory rate for 20 seconds in 60 COPD patients. They demonstrated that tiotropium 
significantly increased inspiratory capacity and $\mathrm{FEV}_{1}$, but did not reduce the decrease in inspiratory capacity following MPH, ie, MPH-induced dynamic hyperinflation, compared with baseline in patients with moderate-to-severe COPD. They suggested that increased baseline inspiratory capacity and lower operational lung volumes resulting from bronchodilation may blunt the effect of MPH-induced dynamic hyperinflation, because the extent of dynamic hyperinflation and decrease in inspiratory capacity with exercise is positively related to resting inspiratory capacity. ${ }^{7}$ Therefore, we corrected $\Delta \mathrm{IC}_{30}$ and $\Delta \mathrm{IC}_{40}$ by $\mathrm{IC}_{20}$, and expressed these as percentage decreases in inspiratory capacity, ie, $\Delta \mathrm{IC}_{30} / \mathrm{IC}_{20}$ and $\Delta \mathrm{IC}_{40} / \mathrm{IC}_{20}$. Both $\Delta \mathrm{IC}_{30} / \mathrm{IC}_{20}$ and $\Delta \mathrm{IC}_{40} / \mathrm{IC}_{20}$ were significantly reduced only for the emphysema phenotype in the tiotropium-treated group. Gelb et $\mathrm{al}^{22}$ also examined the relationship between visual emphysema score and changes in dynamic hyperinflation following MPH after 30 days plus 1.5 hours after the start of tiotropium in 29 patients with moderate-to-severe COPD, and demonstrated that the effects of tiotropium on dynamic hyperinflation were independent of underlying emphysema. In this study, a significant correlation between the low attenuation area score and $\Delta \mathrm{IC}_{40}$ or $\Delta \mathrm{IC}_{40} / \mathrm{IC}_{20}$ was obtained in the tiotropium-treated group but not in the salmeterol-treated group. These different results may be due to the method of MPH used and the severity of emphysema. They directed the patients to achieve a breathing rate of 30 breaths per minute, which is lower than the maximum breathing rate according to our methods, and the emphysema score may be more severe in the emphysema-dominant phenotype in this study.

Reduction of dynamic hyperinflation following treatment with tiotropium in the emphysema dominant phenotype resulted in significantly improved exercise capacity and better health-related quality of life because improvement in dyspnea on effort or exercise tolerance following intervention with pharmacotherapies has been demonstrated to be closely correlated with dynamic hyperinflation, but not with increased $\mathrm{FEV}_{1}{ }^{23}$

In conclusion, tiotropium is more effective than salmeterol regardless of the predominance of emphysema in stable COPD, giving more improvement in exercise tolerance and quality of life as a result of the reduction of dynamic hyperinflation in emphysema dominant COPD.

\section{Acknowledgment}

This study was supported by a grant to the Respiratory Failure Research Group from the Ministry of Health, Labor, and Welfare, Japan.

\section{Disclosure}

The authors report no conflicts of interest in this work.

\section{References}

1. Global Initiative for Chronic Obstructive Lung Disease. Global Strategy for the Diagnosis, Management, and Prevention of Chronic Obstructive Pulmonary Disease. NHLBI/WHO workshop report. Bethesda, National Heart, Lung and Blood Institute, April 2001; Update of the Management Sections. Available at: http://www.goldcopd.com. Accessed March 16, 2011.

2. Nakano Y, Muro S, Sakai H, et al. Computed tomographic measurements of airway dimensions and emphysema in smokers: Correlation with lung function. Am J Respir Crit Care Med. 2000;162:1102-1108.

3. Gelb AF, Zamel N, Hogg JC, Muller NL, Schein MJ. Pseudophysiologic emphysema resulting from severe small-airways disease. Am J Respir Crit Care Med. 1998;158:815-819.

4. Kitaguchi Y, Fujimoto K, Kubo K, Honda T. Characteristics of COPD phenotypes classified according to the findings of HRCT. Respir Med. 2006;100:1742-1752.

5. Fujimoto K, Kitaguchi Y, Kubo K, Honda T. Clinical analysis of chronic obstructive pulmonary disease phenotypes classified using high-resolution computed tomography. Respirology. 2006; 11:731-740.

6. O’Donnel DE, Bertley JC, Chau LK, Webb KA. Qualitative aspects of exertional breathlessness in chronic airflow limitation. Am J Respir Crit Care Med. 1997;155:109-115.

7. O'Donnell DE, Revill SM, Webb KA. Dynamic hyperinflation and exercise intolerance in chronic obstructive pulmonary disease. Am J Respir Crit Care Med. 2001;164:770-777.

8. Belman MJ, Botnick WC, Shin JW. Inhaled bronchodilators reduce dynamic hyperinflation during exercise in patients with chronic obstructive pulmonary disease. Am J Respir Crit Care Med. 1996; 153:967-975.

9. Barr RG, Bourbeau J, Camargo CA, Ram FS. Inhaled tiotropium for stable chronic obstructive pulmonary disease. Cochrane Database Syst Rev. 2005;CD002876.

10. Donohue JF, van Noord JA, Bateman ED, et al. A 6-month, placebocontrolled study comparing lung function and health status changes in COPD patients treated with tiotropium or salmeterol. Chest. 2002; 122:47-55.

11. ATS Committee on Proficiency Standards for Clinical Pulmonary Function Laboratories. ATS Statement: Guidelines for the six-minute walk test. Am J Respir Crit Care Med. 2002;166:111-117.

12. Goddard PR, Nicholson EM, Laszlo G, Watt I. Computed tomography in pulmonary emphysema. Clin Radiol. 1982;33:379-387.

13. Japanese Society of Chest Disease. Standards of pulmonary function tests for Japanese. Jpn J Respir Dis. 1993;31:421-427.

14. Nishida $\mathrm{O}$, Kambe M, Sewake N, et al. Pulmonary function in healthy subjects and its prediction: 5 . Pulmonary diffusing capacity in adults. Jpn J Clin Pathol. 1976;24:941-947.

15. Boren HG, Kory RC, Syner JC, Callahan R. The Veterans Administration-Army cooperative study of pulmonary function. 2 . The lung volume and its subdivisions in normal men. Am J Med. 1966;41:96-101.

16. Van de Woestijne KP, Desager KN, Duiveman EJ, Marchal F. Recommendations for measurement of respiratory input impedance by means of the forced oscillation method. Eur Respir Rev. 1994;19:235-237.

17. Kanda S, Fujimoto K, Komatsu Y, Yasuo M, Hanaoka M, Kubo K. Evaluation of respiratory impedance in asthma and COPD by an impulse oscillation system. Intern Med. 2010;49:23-30.

18. Fujimoto K, Yoshiike F, Yasuo M, et al. Effects of bronchodilators on dynamic hyperinflation following hyperventilation in patients with COPD. Respirology. 2007;12:93-1299. 
19. Casaburi R, Mahler DA, Jones PW, et al. A long-term evaluation of once-daily inhaled tiotropium in chronic obstructive pulmonary disease. Eur Respir J. 2002;19:217-224.

20. Gelb AF, Gutierrez CA, Weisman IM, Newsom R, Taylor CF, Zamel N. Simplified detection of dynamic hyperinflation. Chest. 2004;126:1855-1860.

21. O'Donnell DE, Fluge T, Gerken F, et al. Effects of tiotropium on lung hyperinflation, dyspnea and exercise tolerance in COPD. Eur Respir J. 2004;23:832-840.
22. Gelb AF, Taylor CF, Cassino C, Shinar CM, Schein MJ, Zamel N. Tiotropium induced bronchodilation and protection from dynamic hyperinflation is independent of extent of emphysema in COPD. Pulm Pharmacol Ther. 2009;22:237-242.

23. O'Donnell DE, Lam M, Webb KA. Spirometric correlates of improvement in exercise performance after anticholinergic therapy in chronic obstructive pulmonary disease. Am J Respir Crit Care Med. 1999;160:542-549.

International Journal of COPD

\section{Publish your work in this journal}

The International Journal of COPD is an international, peer-reviewed journal of therapeutics and pharmacology focusing on concise rapid reporting of clinical studies and reviews in COPD. Special focus is given to the pathophysiological processes underlying the disease, intervention programs, patient focused education, and self management protocols.

\section{Dovepress}

This journal is indexed on PubMed Central, MedLine and CAS. The manuscript management system is completely online and includes a very quick and fair peer-review system, which is all easy to use. Visit http://www.dovepress.com/testimonials.php to read real quotes from published authors.

Submit your manuscript here: http://www.dovepress.com/international-journal-of-copd-journal 